\title{
The curability of breast cancer*
}

\author{
MICHAEL BAUM
}

British Medical fournal, 1976, 1, 439-442

"It is now, as it was then, as it may ever be, conceptions from the past blind us to facts which almost slap us in the face."-HALSTED ${ }^{1}$

The day-to-day treatment of breast cancer takes little account of the undoubted uncertainty that exists about its curability. This question should not be shelved as irrelevant for there are lessons to be learnt from this very uncertainty about the biological nature of the disease.

We know now that $20-30 \%$ of patients diagnosed as having early breast cancer will have a normal life expectation after local treatment; about a quarter of these have axillary node infiltration detected in the mastectomy specimen. In the light of these results it is surely complacent to continue our current practice of subjecting at least $70^{\circ}{ }_{0}$ of women with primary disease to a futile mutilating procedure without further questioning.

\section{Does "early" diagnosis improve the cure rate?}

Twenty-five years ago Macdonald" developed the concept of "biological predeterminism" to explain the behaviour of solid tumours in man. His ideas were considered eccentric then but the debate has now begun in earnest.

Macdonald's fundamental point was that if a period of localised tumour growth is associated with either subjective or objective evidence of its presence treatment should be able to produce a $100 \%$

* This paper is based on the opening chapter of Management of Breast Cancer-Early and Late, ed B Stoll, to be published by Heineman in summer, 1976.

University Department of Surgery, Welsh National School of Medicine, Cardiff CF4 4XN

MICHAEL BAUM, MCH, FRCS, senior lecturer and honorary consultant surgeon cure. Provided, therefore, that the patients were educated to recognise these signs and symptoms and then got medical advice without delay cure rates should continue to improve to the $100 \%$ level. But in practice in the USA the age-adjusted death rates for cancer were increasing rather than decreasing. Furthermore, he presented data that suggested that delay on the part of the patient did not affect the stage at presentation of the tumour and that the results of treatment for breast cancer were little different if the patient delayed for one or 12 months. He concluded, therefore, that the outcome of treatment was predetermined by the biological nature of the disease, and commented that "the wide range of biological potential exhibited by human cancer is determined early in the preclinical phase of the disease-apparently early cancer by historical and dimensional criteria may be biologically late."'

McKinnon ${ }^{3}$ took the argument another step forward, pointing out that health education programmes failed to improve mortality rates. He suggested there might be two types of breast cancer: a metastasising incurable variety and a non-metastasising curable variety.

The same theme was taken up again by Devitt in $1965,{ }^{4}$ who argued that if the lymph node-surely the most hostile environment for a cancer cell-becomes the focus of an established metastasis then the biological war between tumour and host is already lost: "Metastases to axillary nodes are an expression of a poor prognosis rather than a determinant." More recently he reviewed the evidence that "early" cancers are slow-growing tumours and "late" cancers are aggressive tumours. The interval between treatment and recurrence and between recurrence and death are longer for those cancers that are diagnosed early than for those diagnosed late: so, he concludes, the timing of initial treatment appears to have little influence on the growth behaviour of breast cancer as reflected in survival rates. ${ }^{5}$

It would be invidious to ignore the recently reported results of the screening programme of the New York Health Insurance Plan. ${ }^{6}$ This study covered 62000 women aged 40-64 years, 31000 of whom were randomly selected and offered screening by clinical examination and mammography on four occasions at yearly intervals. The results indicate that in the screened population breast cancer was detected at an earlier stage and that deaths within seven years of enrolment were reduced by about a third among women over the age of 50 .

This seems powerful evidence for the traditional concept of an arithmetic spatial progression related to duration of the disease. Unfortunately, however, the treatment standards in the two populations were not controlled, and the histological nature of the lesions detected has not been reported. 


\section{Survival after treatment of "curable" breast cancer}

When reporting the results of treatment for breast cancer 10-year survival is usually taken as marking some kind of endpoint. For example, in McKay and Sellars's ' series of nearly 10000 patients there was a 10 -year crude survival rate of $51.1 \%$ for stage 1 disease (T1-2, $\mathrm{N} 1, \mathrm{M0}$ ). But many women with breast cancer are already in their $60 \mathrm{~s}$ or older at diagnosis and will inevitably be dying from incidental disease over these 10 years. Adjustments are therefore usually made according to actuarial life tables to give a corrected survival rate. Using such an adjustment, the overall 10-year survival rate of $30.4 \%$ in McKay and Sellars's series becomes $37.5 \%$.

Unfortunately 10-year survival rates for breast cancer give no real indication of the size of the cured group because of the uncertain history of the disease. Clinicians continually see recurrence of breast cancer 15 to 20 years after apparently successful treatment, making the problem of defining a cured group for breast cancer extremely difficult. Bearing this in mind, the most satisfactory method of defining the cured group is probably that adopted by Haybittle ${ }^{8}$ and illustrated in fig 1. Curve A describes the survival characteristics of an age-matched control population. Curve D describes the survival of patients treated for cancer. The shape of curve D can be attributed to two subpopulations - one a cured group dying at the same rate as the control population (B), and the second an uncured group with an accelerated death rate $(C)$. The point at which curve $D$ parallels curve A can be taken to mean that a greater risk of death no longer exists for the treated group, and so in practical terms they can be considered cured. Extrapolation of curve D from the point of parallelism to the origin gives an index of the population of patients in the originally treated group who were in fact cured.

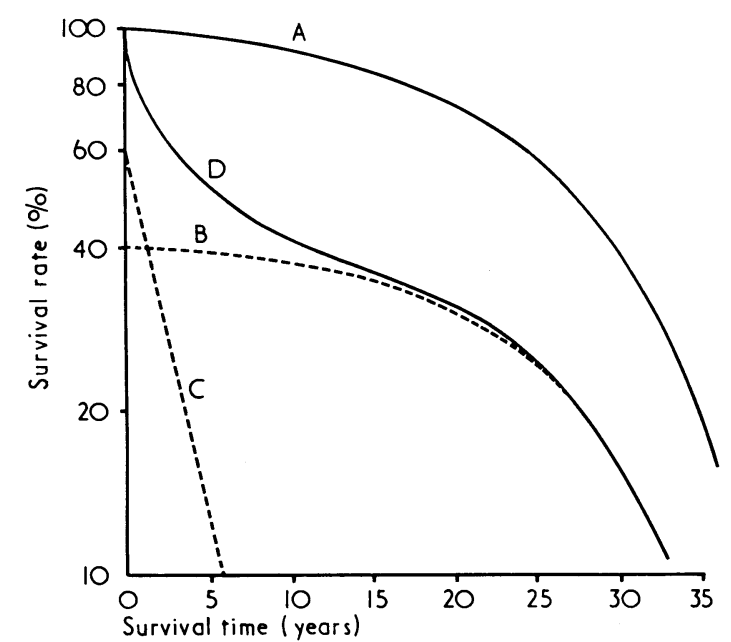

FIG 1 -Survival times of various groups after treatment for cancer: curve A - survival characteristics of age-matched control population; curve Btreated patients with cancer dying at same rate as controls; curve C-treated patients with cancer who are not cured; curve D-composite survival rate (B and C) of all treated patients with cancer. (after Haybittle. ${ }^{8}$ )

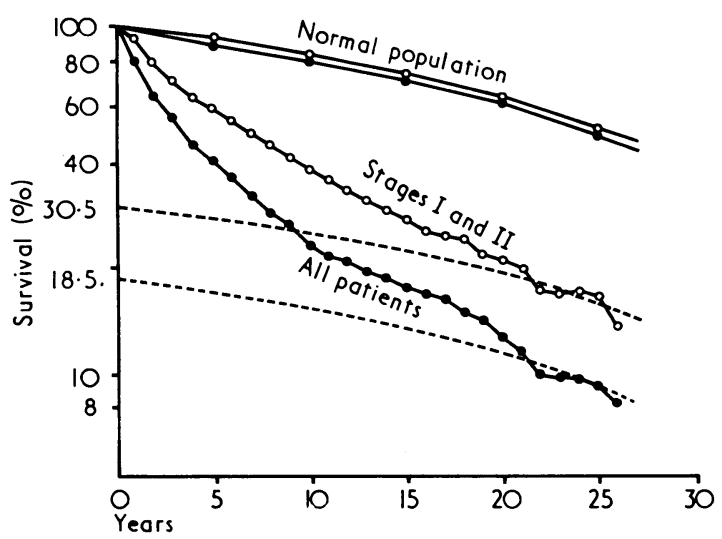

FIG 2-Twenty-five-year survival of patients treated for breast cancer compared with age-matched control population. Broken lines show extrapolation back to zero time of portion of curves that are roughly parallel to those of the corresponding normal population. (Reproduced from paper by Brinkley and Haybittle ${ }^{10}$ by kind permission of the authors and editor of the Lancet.)
Applying these criteria for cure. Brinkley and Haybittle ${ }^{9}$ analysed the long-term results in 704 patients treated in the Cambridge area from 1947 to 1950 . Originally they described a 15 -year crude survival rate of $16 \cdot 6 \%$ (age-corrected to $24 \cdot 3 \%$ ), with a third of the 10 -year survivors failing to live for 15 years. Furthermore, $6^{\circ}$ o of the 15 -year survivors had recurrent disease present. A more recent report on this series, when all patients had been followed up for at least 22 years, gave survival curves up to 25 years for the treated and the control populations shown in fig $2 .^{\circ}$ Parallelism between the expected and the observed curves seems to be occurring after 21 years, providing a cured percentage for the whole group of $18.5 \%$, and a cured percentage for those presenting with early breast cancer of about $30 \%$.

Though the death rates from 20 to 25 years for the treated and control groups were identical, eight out of 23 deaths after 20 years in the treated series were from cancer of the breast- 16 times the number that would be expected in the normal population. This implies that a woman who lives for 20 years with metastatic breast cancer "on her person" is less likely to die of other causes.

\section{OPTIMISM AND PESSIMISM}

Several other series have followed patients for 15 to 30 years and the extremes of opinion have varied from extreme optimism to extreme pessimism.

At the most optimistic Adair et al ${ }^{11}$ reported a 30-year follow up of 1458 patients treated by radical mastectomy in $1940-3$. Only $6.8 \%$ of patients were lost to follow up; 826 died of carcinoma of the breast, 349 died of other causes, and 184 were still alive. A third of the group alive at 30 years had histological evidence of nodal disease in their mastectomy specimen. Only $4 \%$ of all deaths from the original cancer occurred 20 to 30 years after mastectomy. Adair et al considered that 300 of the original series were "practical cures" after 20 years, having achieved a normal life span. The acturial 30-year survival rate was $38 \%$.

Campos $^{12}$ was also reasonably optimistic from his analysis of 391 cases treated by radical mastectomy at the University of Michigan between 1940 and 1955: 99\% of deaths from cancer had occurred by the 15th anniversary, providing an acturial survival rate of $74.2 \%$ for node-negative cases and $20.9 \%$ for node-positive cases. $\mathrm{He}$ was careful not to define his cured population, however, as his analysis showed that death from carcinoma of the breast proceeds as an orderly phenomenon manifested by an exponential function, with a fixed percentage of those at risk dying of the disease each year.

A note of moderate pessimism was sounded by Myers $^{13}$ who reviewed data from 63000 cases of breast cancer treated in the USA between 1940 and 1969. The survival rate after treatment had not improved in the past 20 years; indeed, the survival rate of the treated group relative to an age-matched population continued to show a downward slope up to 25 years, even for those women treated for localised disease. Myers concluded that, "apparently reduction of the excess risk of dying of breast cancer even for localised disease awaits some new therapeutic method."

At the extreme of pessimism was Bond's ${ }^{14}$ follow-up of 6775 cases of early breast cancer treated in the United Birmingham Hospitals. For each of the 25 years after treatment he calculated the ratio of cancer deaths to death from other causes and found that the $15 \%$ of women surviving 25 years still had a 1 in 5 risk of dying of breast cancer when their average age was 80 . His interpretation was that in all cases the cancer had disseminated before diagnosis and was therefore incurable with the methods then available-an interpretation challenged by Haybittle, ${ }^{15}$ whose analysis of the same data showed that the death rate from cancer in the Birmingham series was not constant (which would suggest incurability) but decreased with time. He calculated that well over a quarter of the patients in the Birmingham series could be considered cured, a figure close to that achieved in the Cambridge series.

There is, then, no unanimity about what constitutes a cure in breast cancer. It seems that $20-30 \%$ of women treated for apparently localised breast cancer have a normal life expectation; but doubt remains whether all patients diagnosed as suffering from the disease would ultimately die of it if they lived long enough. Furthermore, how many of these long-term survivors would have lived their natural life span without any treatment?

\section{Natural history of untreated breast cancer}

In spite of the supposed improvements in the diagnosis and treatment of breast cancer, and in the face of an increased public awareness 
of the significance of lumps in the breast, the mortality rates for breast cancer in England and Wales show a disturbing upwards trend (table I). There are four possible explanations. Firstly, more women may be developing the disease-in keeping with the link between breast cancer incidence, age of population, and living standards, though it would be difficult to argue that significant changes in these factors occurred in 1963-73 in England and Wales. Secondly, death registration for breast cancer may be more complete than in the past; this is again unlikely, as regional cancer registries have been fully operational for the period covered by table I. Thirdly, treatment may have become less effective. Again, this is unlikely, as no reported prospective trial for the primary disease has shown any one form of treatment to be better than another. ${ }^{16}$ Finally, and to my mind most probably, the biological nature of the disease may be changing towards a more aggressive form.

TABLE I-Crude mortality rates per 100000 population for breast cancer in England and Wales

\begin{tabular}{c|c|c|c|c|c|c|c}
\hline Reference: & \multicolumn{2}{|c|}{ Campbell } & \multicolumn{4}{|c}{ Registrar General's Statistical Review } \\
\hline Years: & $1952-7$ & $1961-3$ & 1969 & 1970 & 1971 & 1972 & 1973 \\
\hline All ages & 36.5 & $38 \cdot 9$ & 43 & 43 & 45 & 44 & 45 \\
$25-44$ & & & 13 & 14 & 14 & 14 & 14 \\
$45-64$ & & & 77 & 78 & 78 & 78 & 79 \\
$65-74$ & & & 111 & 109 & 118 & 115 & 122 \\
$\geqslant 75$ & & & 161 & 158 & 171 & 169 & 170 \\
\hline
\end{tabular}

The only certain way of understanding the biological nature of a disease is to study its natural history. What do we know about the natural history of breast cancer? In 1880 Gross $^{17}$ published a treatise on a series of 616 cases, $70^{\circ}$ of whom had skin infiltration on presentation and in $25^{\circ}{ }_{0}$ of whom the skin was ulcerated. As a result of the debate then current on the balance of risks of surgery against the meagre benefits it offered he considered it ethical to follow the natural course of the disease in 97 women who received nothing other than "constitutional support."

Skin infiltration appeared on average 14 months after a tumour was first detected; ulceration occurred an average six of months after that; and fixation to the chest wall after a further two months. Invasion of the other breast was seen if the patient lived on average 32 months after the lump first appeared. The average time for the appearance of enlarged axillary nodes was 15 months in those few patients presenting with what today would be staged as T1-2 N0 M0 disease. Twenty-five per cent of these untreated patients had obvious distant metastases within one year and $25^{\circ}$, after three years. Five per cent of this series died five years or more after presentation.

Several other series of patients with untreated breast cancer have been reported, but the study that has attracted the most attention recently is that of Bloom. ${ }^{1 *}$ His data came from the records of 250 women dying of breast cancer in the Middlesex Hospital cancer ward from 1905 to 1933 . Of this group $95^{\circ}$, died of breast cancer. Ninetyseven per cent of the patients presented with stage $1 \mathrm{~V}$ disease. The survival rates from the alleged onset of symptoms were $18^{\circ} \%$ at five years, $3 \cdot 6^{\circ}{ }_{0}$ at 10 years, and $0 \cdot 8^{\circ}$, at 15 years. The mean survival for his series was 2.7 years, which compares well with that of 1728 untreated cases he was able to collate from other sources, with a mean survival of just over three years. The reasons for withholding treatment in Bloom's series are important and were as follows: old age or infirmity in $35 \%$, disease considered too advanced in $30 \%$, early death in $15.4 \%$, and treatment refused in $19 \cdot 6^{\circ}{ }_{0}$.

All these studies can be criticised if used as a baseline against which to judge the curative effect of conventional treatment. Firstly, as with all retrospective uncontrolled series there must have been selection. Why was treatment withheld? With the exception of those refusing treatment most had an exceptionally poor prognosis to begin with. Secondly, these were women in the early years of this century, when many were content to co-exist with their breast lump until they died of old age or were knocked down by a hansom cab.

Finally, the biological nature of the disease may well have changed over the last 50 years. Bloom ${ }^{1 \times}$ tried to refute this suggestion by describing 86 cases with material suitable for the grading of malignancy; the proportion of cases in each histological grade of malignancy was similar to that found today. But histological grading cannot be considered the sole indicator of the biological propensity of an individual cancer; host factors carry equal weight.
Relevant in this respect is an analysis by Fisher and Taylor ${ }^{19}$ of the grade of malignancy and the histological evidence of host response in a large contemporary series of breast cancers and a comparison of their findings with a review of a similar series collected a decade before. In general they found an increase in the less favourable grades of malignancy and a fall in the number of cases showing a lymphocyte stromal response or sinus histiocytosis of the regional nodes. Possibly these early series of untreated cancers may have underestimated the lethal nature of today's disease.

No control group of untreated women could possibly be included in any prospective trial for the treatment of early breast cancer, but a close approximation to such a group came from the report of Mackay and Sellars. ' They published a statistical review of 9742 cases of breast cancer seen at the Ontario cancer clinics between 1938 and 1956 -about $40^{\circ}$. of all new cases of breast cancer in the Province of Ontario in that period. There were 145 well-documented patients who received no treatment of any kind. Though 100 were untreated because of the late stage of their disease of their poor general condition, the rest were unwilling or unable to attend for treatment. As in previous series, they tended to be older, to have delayed longer before presentation, and to have presented with more advanced disease. It was possible with fair accuracy to calculate survival rates from the date of clinical presentation of the disease, though unfortunately the follow-up data were available for only five years. The five-year survival rate from first recorded symptom for the whole untreated group was $35.2 \%$, with a median interval between first symptom and death of 47 months. A most surprising figure, however, was the $68.8 \%$, five-year survival rate after the first symptom in those untreated patients presenting with localised disease. Such a figure does not compare unfavourably with those in many treated series, though this might well have been an artefact resulting from selection and the small number in the sample.

\section{Metastatic potential of breast cancer}

Another aspect of the argument about the curability of breast cancer is the possibility that a lump removed from the patient who thereafter lives a normal span of years may be claimed not to have been cancer at all. The absoluteness of a diagnosis of cancer based on the histological examination of a biopsy specimen may always be queried - pathologists readily admit that there are grey areas in the histopathology of tumours. The dividing lines between epithelial hyperplasia, intraduct carcinoma, and early invasive ductal carcinoma are not clear-cut. Furthermore, sclerosing adenosis is notoriously difficult to diagnose, and Urban and Adair ${ }^{20}$ reported that $90 \%$ of such cases were being classified as carcinoma up until 1949 .

Though mistakes would be unlikely among the subgroup with axillary metastases found at mastectomy, there must inevitably be some doubts about the true diagnosis in the long-term survivors after mastectomy. None the less, it would help in the development of the subsequent argument if it were conceded that all apparently cured women have had a truly invasive carcinoma of the breast.

The factors that determine when a localised cancer will disseminate cells into its lymphatic drainage or into the general circulation are not fully understood; nor are the factors that decide whether a shed malignant cell will successfully establish a metastasis. Both events probably depend on the rate of replication of the cancer cell, the invasive aggressiveness of the cancer, the anatomical access to lymph or vascular channels, the age of the tumour, the defence mechanisms of the patient, and factors within the "soil" of the target sites.

It is reasonable to assume that the more cell replications there are the greater the opportunity for dissemination. If the growth rate of a tumour is assumed to be constant (expressed by its doubling time), and the size of the tumour at diagnosis is measured, the number of doublings that have occurred in the preclinical phase of its growth can be estimated roughly. If the number of doublings between inception of the growth and clinical presentation are small then the chances of spread before treatment are small. If the clinical phase of tumour growth merely represents the last chapter of a prolonged silent but sinister story of cellular proliferation, however, then if that tumour has any metastatic potential spread will have occurred before diagnosis is possible and the disease must be considered incurable by conventional local treatment.

Several authors have attempted to estimate doubling times. Collins et $a l^{21}$ estimated growth rates from serial chest $x$-ray pictures of patients with pulmonary metastases. Philipe and Le $\mathrm{Gal}^{22}$ used cutaneous nodules, while Kusama et al ${ }^{23}$ calculated the doubling time by observing the growth patterns of the primary lesion. Gershon-Cohen et al $^{24}$ reviewed serial mammograms of the lesion taken before biopsy 
in 18 patients with breast cancer and showed that the doubling time varied from 23 to 209 days. The tumours were divided into fast growing, with a doubling time or less than 75 days, slow growing, with a doubling time of more than 150 days, and an intermediate group with doubling times from 75 to 150 days. On the premise that a clinically detectable tumour of $1.0 \mathrm{~cm}$ has undergone 30 doublings if the original cell was $10 \mu \mathrm{m}$ in diameter, they estimated that fastgrowing tumours originated about two years before clinical presentation while slow growing tumours would originate up to 17 years before becoming clinically diagnosable.

They therefore suggested that on average treatment is started only during the final third of the life cycle of breast cancer. Yet in their experience a difference of $1.5 \mathrm{~cm}$ in the diameter of a tumour, representing only three or four doublings, increases the metastatic rate from $30^{\prime \prime}$ " to $60^{\prime \prime}{ }^{\prime}$. Thus, while most tumours seemed to have had ample opportunity to disseminate before clinical presentation some needed to attain a certain clinical size before colonising and by definition should be curable be entirely local measures.

Bond $^{14}$ reached a less optimistic conclusion. His plot of the size of the tumour at presentation against the alleged duration from first detection by the patient in 9341 cases yielded two lines, which he interpreted as suggesting either one type of tumour with a changing growth rate or two types of tumour of different growth rates. The latter explanation suggested the existence of fast-growth tumours with a 90 -day doubling time and slow-growth tumours with a 450-day doubling time. The former would originate about eight years before detection and the latter might arise 42 years before detection. Extrapolating the data to the time of appearance of bone and pulmonary metastases of a given diameter Bond suggested that a primary tumour only 10 cells in diameter might originally be responsible for the successful establishment of a proportion of these secondary growths. Furthermore, a primary tumour of only $1 \mathrm{~mm}$ in diameter containing $10^{\circ}$ cells was capable of metastasising and causing death in $20^{\circ}$ " of patients within eight years.

These and similar arguments are, however, based on three unproved assumptions: firstly, that the growth rates of the primary tumour and its metastases are constant throughout the life cycle of the tumour; secondly, that, once established, the primary tumour or its secondary deposits develop full growth rate immediately without any latent period; and, thirdly, that all tumour masses consist of malignant cells packed together in a homogenous sphere and are all subdividing synchronously.

\section{Alternative concept of the nature of breast cancer}

Most cases of breast cancer seen in practice must be considered incurable. Our failure to improve survival rates has been due to clinicians rigidly maintaining obsolete concepts of the nature of the disease. If the current generation is to reduce mortality clinicians must first reject the simplistic mechanistic view of the disease that has led to more and more aggressive local treatment.

Breast cancer is a systemic disease until proved otherwise. We must abandon the assumption that dissemination has not occurred until it is proved. Next, it has to be accepted that breast cancer is not a homogeneous entity but behaves as a multitude of diseases. Slack et al ${ }^{25}$ produced a mathematical model from the results of the National Surgical Adjuvant Breast Project that suggested that there were at least two types of breast cancer. A fifth of all cases appeared to be fast-growing tumours, carrying three to eight times the average risk of nodal metastasis and two to six times the average risk of occult metastases, for which there was a short delay in reporting symptoms; the other four-fifths comprised slow-growing tumours. Even this is probably an oversimplification related to the limitations of this type of mathematical analysis.

I would like to propose theoretical groupings of breast cancer types based on the data described in this paper. These are shown in table II together with the implications for treatment of each type. Other similar theoretical classifications are possible.

We can suit treatment to the individual only if we can identify the type of breast cancer on presentation. At present the best we can do is recognise the exceptionally poor prognostic significance of positive nodal histological findings or positive bone scans and introduce systemic treatment for these patients at an early stage.
With greater refinement in prognostic indicators and with the use of more effective non-toxic anti-cancer agents the appalling mortality rate for breast cancer will finally be controlled. Available resources might better be turned in this direction

TABLE II-Theortical gioupings of breast cancer

\begin{tabular}{|c|c|c|}
\hline Type & Biological nature & Therapeutic implications \\
\hline${ }_{\mathrm{II}}^{\mathrm{I}}$ & $\begin{array}{l}\text { Non Metastasising (rare) } \\
\text { Single focus } \\
\text { Multifocal } \\
\text { Metastasises to regional lymph } \\
\text { nodes only with late z'uscular } \\
\text { spread (rare) }\end{array}$ & $\begin{array}{l}\text { Curable by "lumpectomy" } \\
\text { Curable by simple mastectomy } \\
\text { Curable by radical mastectomy } \\
\text { or simple mastectomy plus } \\
\text { regional radiotherapy. Node } \\
\text { dissection or irradiation could } \\
\text { be performed electively rather } \\
\text { than prophylacticaly }\end{array}$ \\
\hline$\stackrel{\text { III }}{A}$ & $\begin{array}{l}\text { Metastasising ria blood stream } \\
\text { Disseminates before cither } \\
\text { radiographically or } \\
\text { clinically detectable. When } \\
\text { nodes involved acts as } \\
\text { index of unfavourable } \\
\text { tumour host balance } \\
\text { (probably most common } \\
\text { type). }\end{array}$ & $\begin{array}{l}\text { Incurable by local therapy alone, } \\
\text { demands adjuvant systemic } \\
\text { therapy }\end{array}$ \\
\hline B & $\begin{array}{l}\text { Disseminates in period } \\
\text { between becoming } \\
\text { radiologically apparent } \\
\text { but before clinically } \\
\text { obvious (rare) }\end{array}$ & $\begin{array}{l}\text { Curable by local therapy alone } \\
\text { if detected at mass screening } \\
\text { by mammography }\end{array}$ \\
\hline C & $\begin{array}{l}\text { Disseminates any time after } \\
\text { it becomes clinically } \\
\text { detectable (rare) }\end{array}$ & $\begin{array}{l}\text { Curable by local therapy alone } \\
\text { if detected by patient herself } \\
\text { or at mass screening by } \\
\text { clinical examination }\end{array}$ \\
\hline
\end{tabular}

rather than in the establishment of a national screening programme that will benefit only that small group of patients whose cancer metastasises as it grows from radiological to clinical proportions. This is a relatively short period in the life cycle of any breast cancer.

I thank Dr John Haybittle for his helpful advice and for supplying important source material and Miss Sheila Herbert for typing and correcting the innumerable drafts of this text.

\section{References}

${ }^{1}$ Halsted, W S, Surgical Papers, vol 2. Baltimore, Johns Hopkins Press, 1924.

2 Macdonald, I, Surgery, Gynecology and Obstetrics, 1951, 92, 443.

${ }^{3}$ McKinnon, N E, Lancet, 1954, 1, 251.

${ }^{4}$ Devitt, J E, Canadian Medical Association fournal, 1965, 93, 289.

${ }^{5}$ Devitt, J E, in Risk Factors in Breast Cancer, ed B A Stoll, p 110. London, Heinemann, 1976.

${ }^{6}$ Strax, P, et al, Cancer, 1967, 20, 2184.

7 Mackay, E N, and Sellars, A H, Breast Cancer at the Ontario Cancer Clinics, 1938-1956. A Statistical Review. Ontario, Medical Statistics Branch, Ontario Department of Health, 1965.

${ }^{8}$ Haybittle, J L, Anglo-German Medical Review, 1964, 2, 422.

${ }^{9}$ Brinkley, D, and Haybittle, J L, British fournal of Radiology, 1968, 41, 215.

10 Brinkley, D, and Haybittle, J L, Lancet, 1975, 2, 95.

11 Adair, F, et al, Cancer, 1974, 33, 1145.

12 Campos, J L, British fournal of Radiology, 1972, 45, 31.

${ }^{13}$ Myers, M H, in Breast Cancer: A Challenging Problem, ed M L Griem, et al, p 87. London, Heinemann, 1973.

${ }^{14}$ Bond, W H, in The Treatment of Carcinoma of the Breast, p 1. Amsterdam, Excerptia Medica, 1968.

${ }^{15}$ Haybittle, J L, British fournal of Radiology, 1968, 41, 639.

16 Fisher, B, Cancer, 1973, 31, 1271.

17 Gross, S W, A Practical Treatise of Tumours of the Mammary Gland. New York, Appleton, 1880.

18 Bloom, H J G, in Prognostic Factors in Breast Cancer, ed A P M Forrest and P B Kunkler. Edinburgh, Livingstone, 1968.

19 Fisher, E R, and Taylor, M, Cancer, 1973, 32, 1380

20 Urban, J A, and Adair, F E, Cancer, 1949, 2, 625.

${ }^{21}$-Collins, V P, Loeffler, R K, and Tivey, H, American fournal of Roentgenology and Radiation Therapy, 1956, 76, 988.

2:2 Philippe, F, and Le Gal, Y, Cancer, 1968, 21, 461.

${ }^{23}$ Kusama, S, et al, Cancer, 1972, 30, 594.

${ }^{24}$ Gershon-Cohen, J, Berger, S M, and Klickstein, H S, Cancer, 1963, 16, 961.

${ }^{25}$ Slack, N H, Blumenson, L E, and Bross, I D J, Cancer, 1969, 24, 960.

${ }^{26}$ Campbell, H, in Prognostic Factors in Breast Cancer, ed A P M Forrest and P B Kunkler, p 50. Edinburgh, Livingstone.

27 Registrar General's Statistical Review of England and Wales 1973, part I (A) Medical. London, HMSO, 1974. 